Open Access

\title{
Inhibitory effects of Mycoepoxydiene on macrophage foam cell formation and atherosclerosis in ApoE-deficient mice
}

Xiaochun Xia', Yang Li ${ }^{2}$, Qiang Su${ }^{3}$, Zhengrong Huang ${ }^{1}$, Yuemao Shen ${ }^{4}$, Weihua $\mathrm{Li}^{{ }^{*}}$ and Chundong $\mathrm{Yu}^{2^{*}}$

\begin{abstract}
Background: Mycoepoxydiene (MED) is a polyketide that can be isolated from a marine fungus and is associated with various activities, including antitumor and anti-inflammatory functions. However, its effects on atherosclerosis remain unknown. Macrophage-derived foam cells play crucial roles in the initiation and progression of atherosclerotic plaques. In this study, we investigated the effects of MED on oxidized low-density lipoprotein (ox-LDL)-induced macrophage foam cell formation and activation, and on high fat diet (HFD)-induced atherosclerosis in ApoE-deficient $\left(A p o E^{-1-}\right)$ mice.
\end{abstract}

Results: Our findings show that MED could significantly inhibit ox-LDL-induced macrophage foam cell formation and suppress the expression of lectin-like oxidized low-density lipoprotein receptor-1 (LOX-1), which is a receptor for ox-LDL. Additionally, MED could significantly inhibit the secretion of proinflammatory cytokines, such as tumor necrosis factor (TNF-a), interleukin (IL)-6, and IL-1ß. Mechanistically, MED inhibited NF-KB activation by blocking IKB-a degradation and reducing NF-KB DNA binding activity. Moreover, MED dramatically reduced the occurrence of HFD-induced atherosclerotic lesions in $\mathrm{ApoE}^{-1-}$ mice.

Conclusions: Our study shows that MED can inhibit macrophage foam cell formation and activation by inhibiting NF-KB activation, thereby protecting $\mathrm{ApoE}^{--}$mice from HFD-induced atherosclerosis. Our findings suggest that MED might be a potential lead compound for the development of antiatherosclerotic therapeutics.

Keywords: Mycoepoxydiene, ox-LDL, Macrophage, Foam cell, Atherosclerosis

\section{Background}

Atherosclerosis, a chronic inflammatory disease that is characterized by the accumulation of lipids and fibrous elements that result from interactions between vascular cells and inflammatory cells, is a leading cause of mortality in developed countries $[1,2]$. Studies have shown that inflammation plays a critical role in all stages, from initiation through progression, and ultimately drives the thrombotic complications of atherosclerosis. Ox-LDL plays a critical role in triggering proinflammatory and pro-oxidant events in the initiation, propagation, and

\footnotetext{
* Correspondence: liweihuaxm@hotmail.com; cdyu@xmu.edu.cn

${ }^{1}$ The First Affiliated Hospital of Xiamen University, Xiamen, Fujian 361005, China

${ }^{2}$ State Key Laboratory of Cellular Stress Biology, Innovation Center for Cell Signaling Network, School of Life Sciences, Xiamen University, Xiang-An South Road, Xiamen, Fujian 360112, China

Full list of author information is available at the end of the article
}

activation of atherosclerosis [3, 4]. Ox-LDL is taken up via the scavenger receptor expressed by macrophages, which turns macrophages into lipid-laden foam cells [5]. Additionally, ox-LDL stimulates macrophages to release proinflammatory cytokines such as IL-1 $\beta$ and TNF- $\alpha$ [6].

LOX-1, which is a lectin-like receptor for ox-LDL in endothelial cells, smooth muscle cells, and macrophages [7-9], plays important roles in atherosclerosis development [10]. The binding of ox-LDL to LOX-1 leads to ox-LDL uptake by macrophages and foam cell transformation [11]. NF- $\mathrm{kB}$, which is a downstream factor of LOX-1, is a pivotal transcription factor involved in atherosclerosis. NF- $\mathrm{kB}$ activation has been observed at different stages of atherosclerosis, from plaque formation to its destabilization and rupture [12, 13]. LOX-1 can be dynamically up-regulated by various proinflammatory, pro-oxidative, and mechanical stimuli [14-16]. Many antiatherosclerotic drugs, such as stains, exert their 
function at least in part via direct or indirect downregulation of LOX-1 expression $[17,18]$.

Mycoepoxydiene (MED) is a novel polyketide that can be isolated from the marine fungus Diaporhte sp. (D.sp.) HLY-1 and was discovered in submerged rotten leaves of Kandelia candel in a mangrove forest in Fujian Province, China [19]. It contains an $\alpha, \beta$-unsaturated-lactone moiety and an oxygen-bridged cyclooctadiene core [20]. Previous studies have shown that MED could exert antimicrobial and antitumor activities [19, 21]. Recently, we have showed that MED could inhibit LPS-induced inflammatory responses, ovariectomy-induced osteoporosis, and allergic responses in mice [22-24]. In macrophages, MED can significantly inhibit the LPS-induced expression of proinflammatory mediators, such as TNF- $\alpha$, IL-6, IL-1 $\beta$ and nitric oxide (NO) through blocking the activation of both NF- $\kappa B$ and MAPK pathways [22]. In mast cells, MED can significantly suppress antigen-stimulated degranulation and cytokine production by blocking the MAPK pathways. Because MED displays an anti-inflammatory activity, we wanted to determine whether it could inhibit atherosclerosis, which is related to the inflammatory response [25-27]. Herein, we show that MED can inhibit foam cell formation and cytokine production induced by ox-LDL in macrophages and protect $A p o E^{-/-}$mice from atherosclerosis by blocking the NF-KB signaling.

\section{Results}

\section{MED significantly suppresses macrophage foam cell} formation

Foam cells are pathogenic cells in atherosclerosis that are derived from monocytes/macrophages and vascular smooth muscle cells. RAW264.7 cells, which share many features in common with macrophages, can be induced to form foam cells by ox-LDL in vitro. To explore whether MED affected foam cell formation, RAW264.7 cells were treated with ox-LDL in the absence or presence of different concentrations of MED for $24 \mathrm{~h}$ and were then stained with Oil-red O solution. First, we detected the cytotoxicity of MED to RAW 264.7 cells using a MTT assay. As shown in Fig. 1a, MED showed no cytotoxicity to RAW 264.7 cells in a concentration range between 1 and $10 \mu \mathrm{M}$; therefore, these concentrations of MED were used in the subsequent in vitro experiments. A total of $35 \%$ of RAW264.7 cells displayed foamy characteristics with oil red staining of lipid droplets after incubation with ox-LDL for $24 \mathrm{~h}$, but MED treatment significantly reduced the foam cell formation in a dose-dependent manner (Fig. 1b, c).

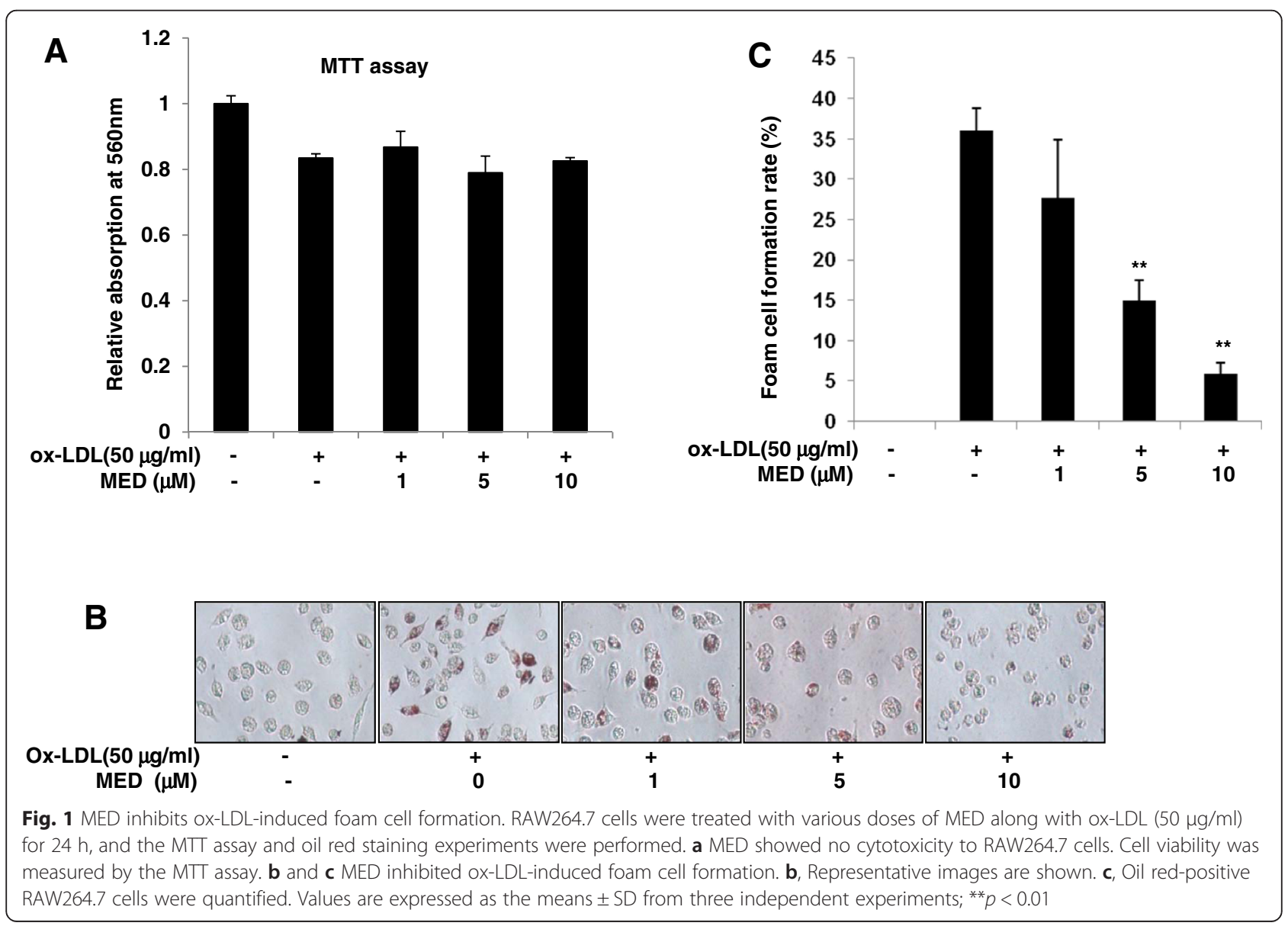




\section{MED inhibits ox-LDL-induced LOX-1 expression in macrophages}

LOX-1 is a lectin-like receptor for ox-LDL in endothelial cells, smooth muscle cells, and macrophages, which are three important cell types involved in the development of atherosclerosis [10]. LOX-1 expression can be induced by ox-LDL in a feed-forward fashion. To determine whether MED can inhibit foam cell formation by blocking ox-LDLinduced LOX-1 expression, RAW 264.7 cells were treated with ox-LDL in the absence or presence of MED for $24 \mathrm{~h}$; the LOX-1 protein levels were then evaluated by western blotting. As shown in Fig. 2a, MED significantly inhibited the LOX-1 protein levels in a dose-dependent manner. To determine whether the reduced expression level of LOX-1 could be attributed to the reduced mRNA levels of LOX-1, real-time PCR was performed. As shown in Fig. 2b, MED significantly suppressed the mRNA levels of LOX-1, which indicated that MED may inhibit ox-LDL-induced LOX-1 expression at the transcriptional level.

\section{MED can suppress proinflammatory cytokine expression in macrophages induced by ox-LDL}

It has been demonstrated that macrophages are abundant in plaque lesions and play a central role in atherosclerosis development [28]. In addition to inducing foam cell formation, ox-LDL can activate macrophages to produce proinflammatory cytokines, such as TNF- $\alpha$, IL- 6 , and IL-
$1 \beta$, to promote atherosclerosis. To examine whether MED could affect the ox-LDL-induced production of TNF- $\alpha$, IL-6, and IL-1 $\beta$ in macrophages, the production of these cytokines by ox-LDL-stimulated macrophages was measured in the absence or presence of MED. As shown in Fig. 3a, MED significantly inhibited the ox-LDL-induced production of TNF- $\alpha$, IL- 6 , and IL-1 $\beta$. Furthermore, we found that MED significantly suppressed the mRNA levels of TNF- $\alpha$, IL-6, and IL-1 $\beta$ in RAW 264.7 cells (Fig. 3b), which indicated that MED might inhibit ox-LDL-induced proinflammatory cytokine expression at the transcriptional level.

\section{MED inhibits ox-LDL induced activation of NF-KB signaling in macrophages}

It has been shown that ox-LDL can induce the expression of LOX-1 and proinflammatory cytokines, such as IL-1 $\beta$ and TNF- $\alpha$, through the activation of NF- $\mathrm{kB}$ signaling $[2,29]$. To explore whether MED could inhibit NF- $\mathrm{kB}$ signaling, the effects of MED on ox-LDL-induced NF- $\mathrm{kB}$ activation in RAW 264.7 cells were examined. As shown in Fig. 4a and b, MED significantly suppressed ox-LDLinduced IкB- $\alpha$ degradation, nuclear p65 expression, and the DNA binding activity of NF- $\mathrm{kB}$ at concentrations of 5 and $10 \mu \mathrm{M}$ in macrophages, which indicated that MED could inhibit the activation of NF- $\mathrm{B}$ signaling.
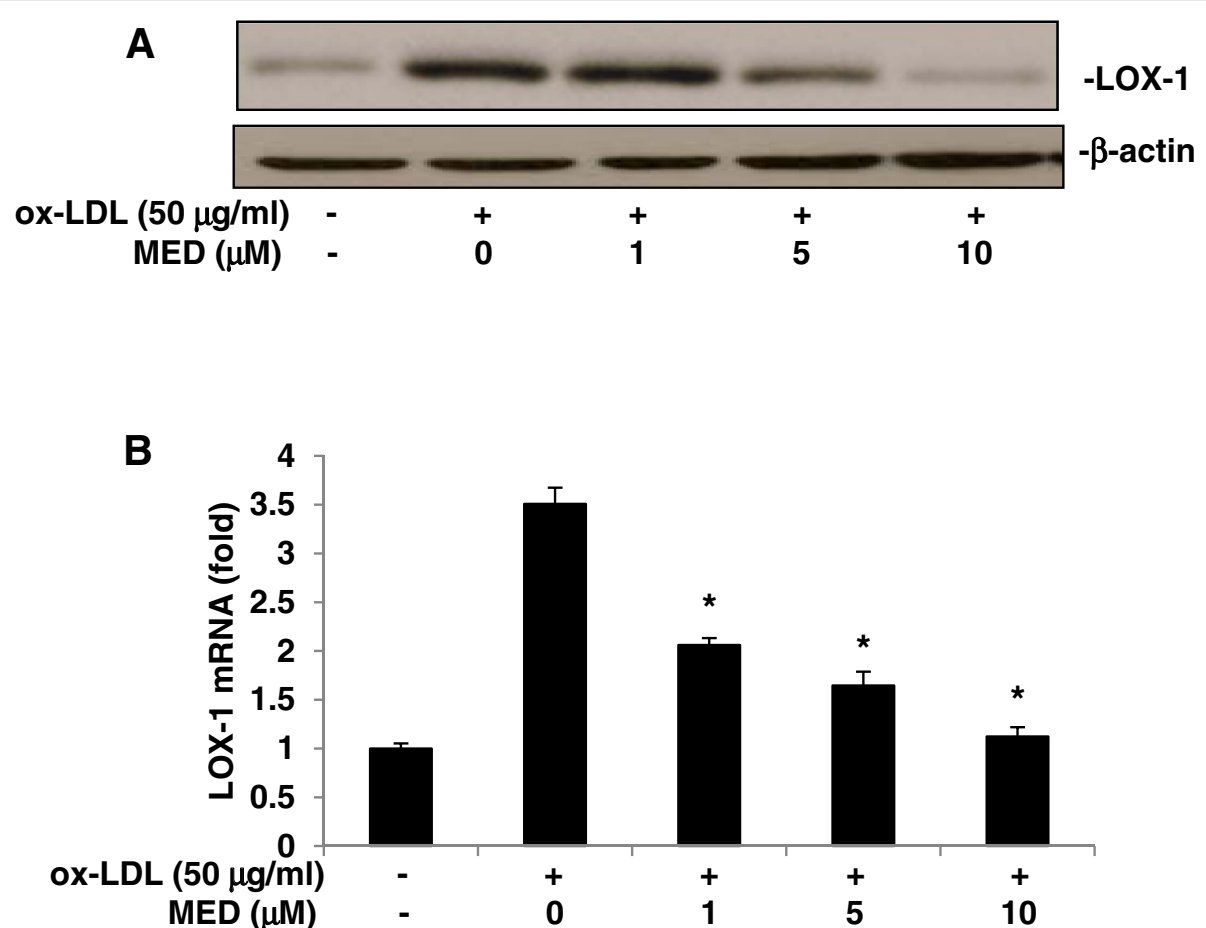

Fig. 2 MED attenuates ox-LDL-induced LOX-1 expression. RAW264.7 cells were treated with ox-LDL (50 $\mu \mathrm{g} / \mathrm{ml})$ in the absence or presence of MED for 24 h. a LOX-1 protein levels were measured by western blot analysis. b LOX-1 mRNA levels was evaluated by real-time PCR. Values indicate means \pm SD from three independent experiments; ${ }^{*} p<0.05$ 


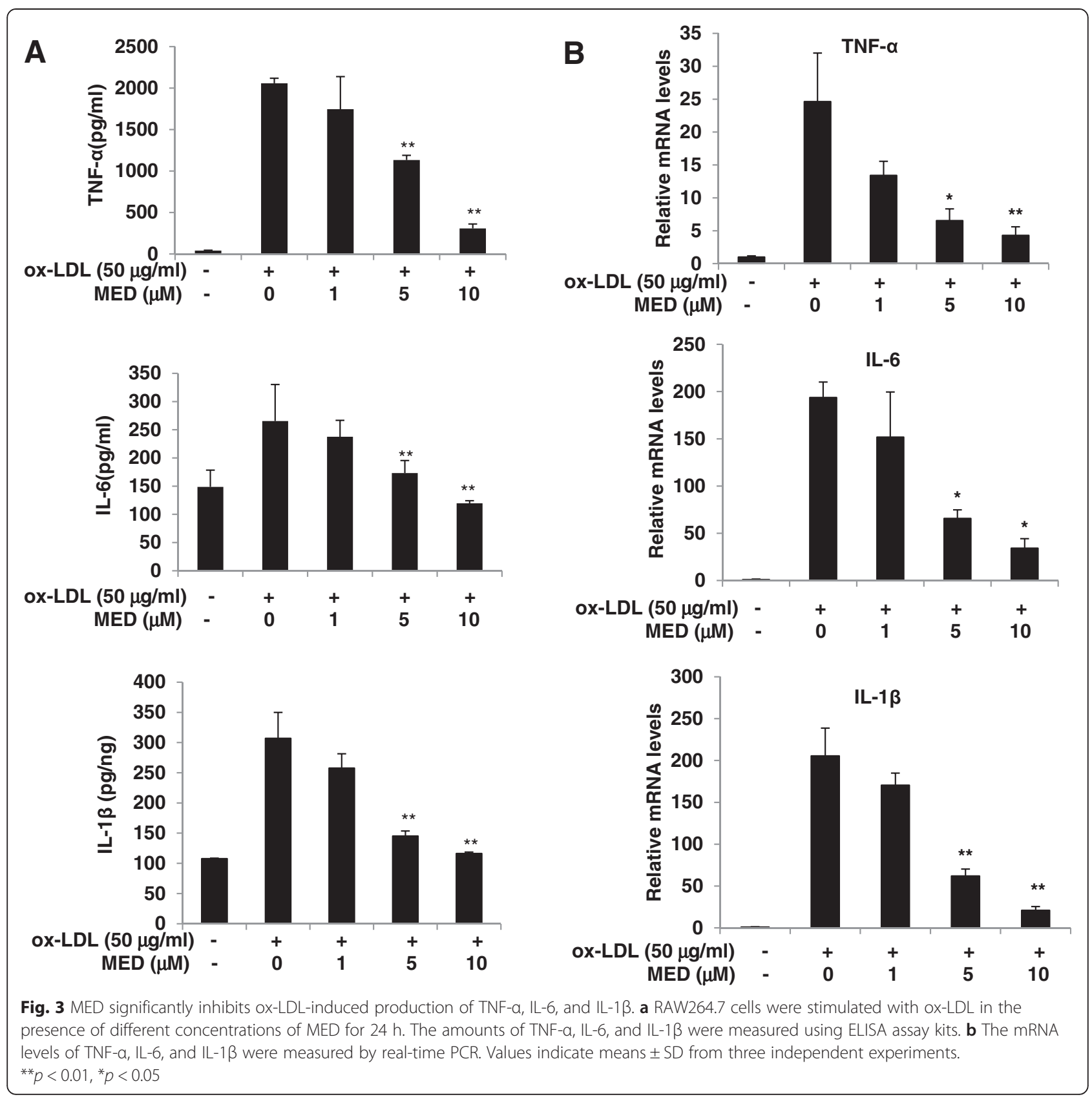

MED effectively reduces atherosclerotic lesions in $\mathrm{ApoE}^{-/-}$mice

Because high-fat diet (HFD)-induced arterial lesions in $A p o E^{-/-}$mice have many features in common with human atherosclerosis, $A p o E^{-/-}$mice are considered to be a good animal model of atherosclerosis [30]. Because MED could effectively inhibit ox-LDL-induced macrophage foam cell formation and activation in vitro, we assessed whether MED could suppress HFD-induced atherosclerosis in $A p o E^{-/-}$mice. $A p o E^{-/-}$mice were fed with a high-fat diet, and vehicle (PBS) or MED $(4 \mathrm{mg} / \mathrm{kg} /$ day) was injected every 2 days for 2 months, then, the atherosclerotic lesions in the descending aorta were detected by Sudan IV staining. As shown in Fig. 5a and b, MED significantly suppressed the area of lesions compared with the PBS control group, which demonstrated that MED can suppress atherosclerosis in vivo. Additionally, we found that there was no significant difference in body weight gain between the PBS control group and MED group during the 8 weeks of HFD feeding (Additional file 1: Figure S1), which indicated that MED caused no apparent toxicity in mice after long-term MED treatment.

To determine whether MED could suppress inflammation in mice after 8 weeks of HFD feeding, the levels of 
A
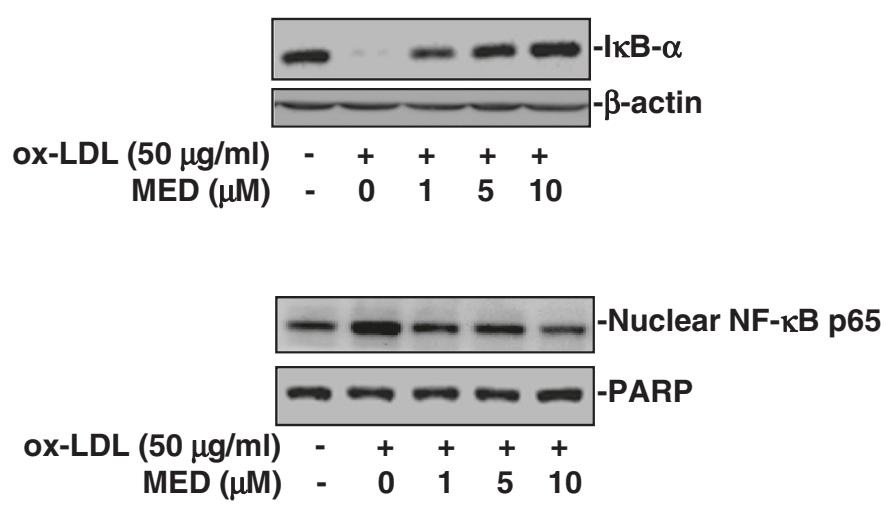

B

MED $(\mu \mathrm{M}) \quad-\quad 0 \quad 5 \quad 10$

ox-LDL $(50 \mu \mathrm{g} / \mathrm{ml}) \quad-\quad+\quad+\quad+$ LPS

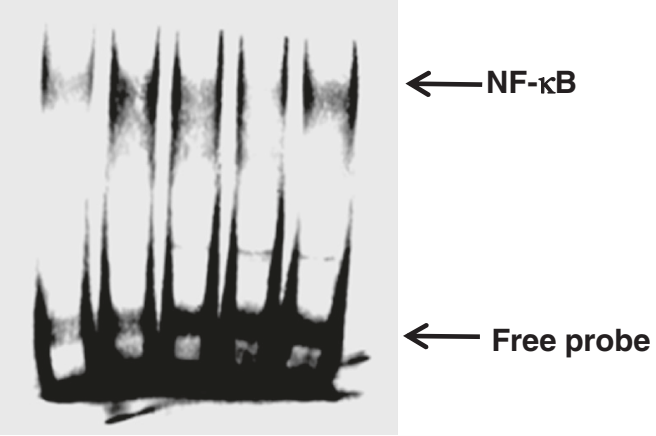

Fig. 4 MED inhibits ox-LDL-induced activation of NF-KB signaling. a and b RAW264.7 cells were stimulated with ox-LDL in the absence or presence of MED for $3 \mathrm{~h}$, and then western blot analysis of IKB- $a$ and nuclear p65 was performed. Representative images of three independent experiments are shown. $\mathbf{a}$, The effect of MED on ox-LDL-induced IKB-a degradation and nuclear NF-KB p65 expression. $\mathbf{b}$, The effect of MED on ox-LDL-induced NF-KB DNA binding activity. RAW264.7 cells were stimulated with ox-LDL in the absence or presence of MED for $3 \mathrm{~h}$, and then nuclear extracts were obtained for EMSA

\section{A}

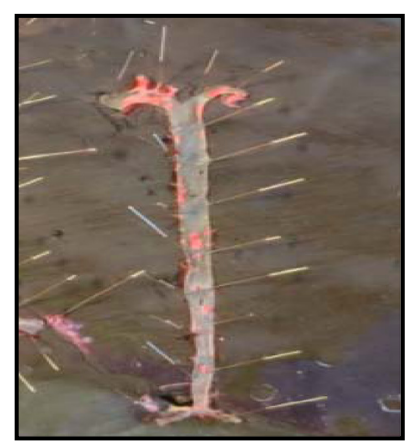

PBS

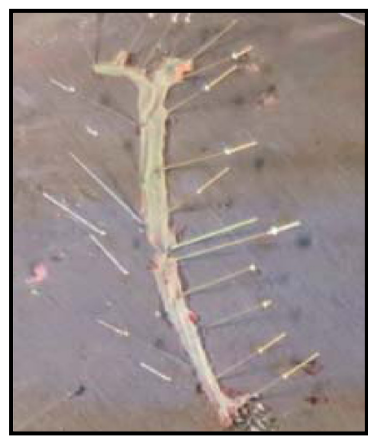

MED
B

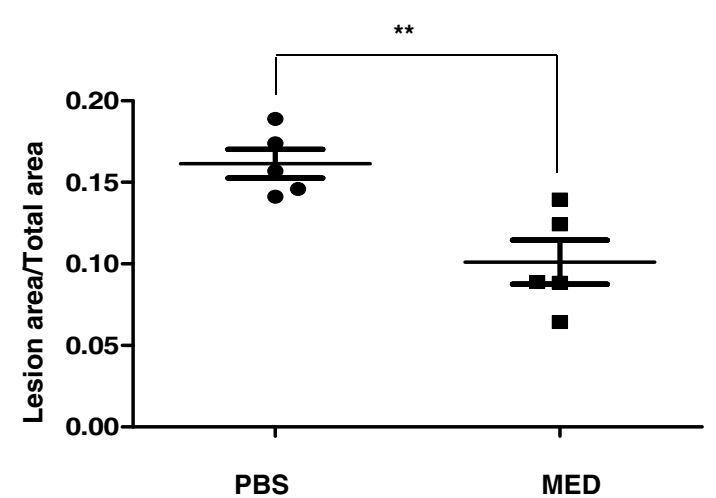

Fig. 5 MED effectively reduces atherosclerotic lesions in HFD-fed $A p o E^{-1}$ mice. a HFD-fed mice were injected with PBS or $4 \mathrm{mg} / \mathrm{kg} / \mathrm{day}$ MED every other day for 8 weeks, respectively. At the end points, mice were sacrificed, and atherosclerotic lesions in the descending aorta were detected by Sudan IV staining. b Quantitative analysis of atherosclerotic lesion sizes. Data are presented as the means \pm S.D; $n=5$ per group. ${ }^{* *} p<0.01$ 
inflammatory cytokines, including TNF- $\alpha$, IL-6, and IL$1 \beta$, in plasma and the aortic arch of HFD-fed ApoEdeficient mice were measured. As shown in Fig. 6a and b, MED suppressed the protein levels of TNF- $\alpha$, IL- 6 , and IL-1 $\beta$ in plasma and the mRNA levels of TNF- $\alpha$, IL- 6 , and IL-1 $\beta$ in the aortic arch. Furthermore, MED suppressed nuclear p65 expression in the aortic arch of HFD-fed ApoE-deficient mice (Additional file 2: Figure 2S). These results indicate that MED can inhibit atherosclerosis at least in part by suppressing inflammation in vivo.

\section{Discussion}

Atherosclerosis is considered a type of chronic inflammation. The differentiation of macrophages to lipid-laden foam cells is a pivotal process in the development of the atherosclerosis [31]. The transformation of foam cells can be attributed to the dysregulated uptake of modified LDL by macrophages $[32,33]$. Ox-LDL is a critical factor in the initiation and progression of atherosclerosis, especially for foam cell formation. It is thought that uptake of ox-LDL by macrophage scavenger receptors is largely responsible for disease progression. As a receptor for ox-LDL, LOX-1 accumulates in human and animal atherosclerotic lesions in vivo [34]. It has been shown that LOX-1 functions as a proinflammatory adhesion molecule in leukocytes and platelets [35]. LOX-1 affects several inflammatory stages of atherosclerosis, such as macrophage foam cell formation and activation [16]. It has been reported that the deletion of LOX-1 reduces atherogenesis in LDLR-knockout mice that are fed a high cholesterol diet [36], thus highlighting the important role of LOX-1 in atherosclerosis. In our present study, MED could significantly inhibit RAW 264.7 cells transformation into foam cells and LOX1 expression induced by ox-LDL, which indicated that the suppression of LOX-1 expression by MED contributes to its inhibitory effects on macrophage foam cell formation.

It has been shown that LOX-1 is involved in inflammatory reactions and is an important mediator of
A
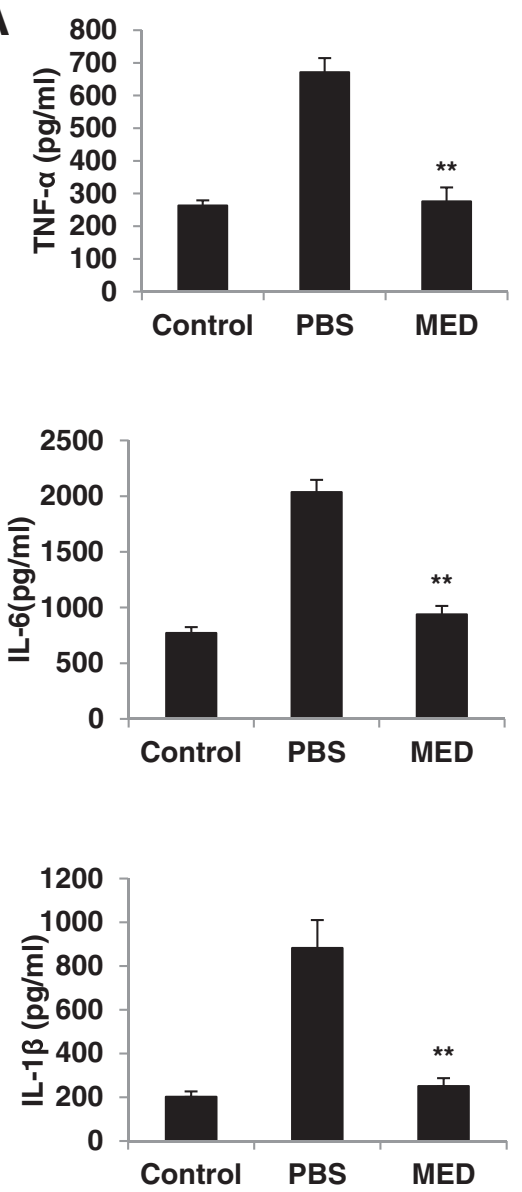

B
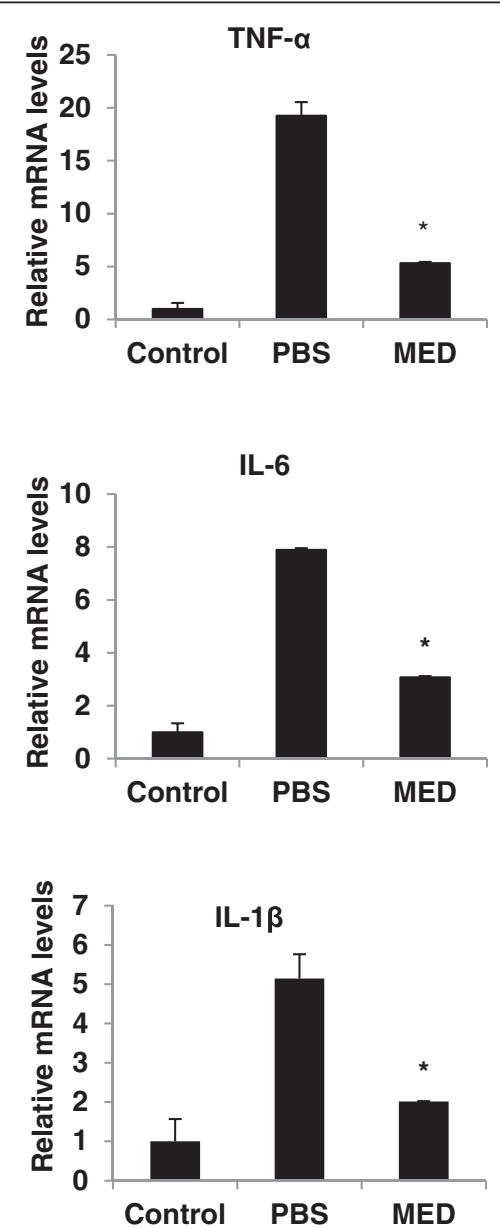

Fig. 6 Inhibitory effects of MED on pro-inflammatory cytokine expression in mice. a The amounts of TNF-a, IL-6, and IL-1 $\beta$ in plasma were measured using ELISA assay kits. $\mathbf{b}$ Expression levels of the inflammatory genes, including TNF-a, IL-6, and IL-1 $\beta$, were measured by real-time PCR in the aortic arch isolated from mice; Control, normal chow-fed group; PBS, HFD-fed and PBS-treated group; MED, HFD-fed and MED treated group. Data indicate means $\pm S . D ; n=5$ per group; ${ }^{* *} p<0.01,{ }^{*} p<0.05$ 
inflammation [37]. Macrophages produce abundant amounts of pro-inflammatory cytokines, such as TNF- $\alpha$, IL-6, and IL-1 $\beta$, to promote atherosclerosis. Herein, we have shown that MED can significantly inhibit the oxLDL-induced expression of TNF- $\alpha$, IL- 6 , and IL- $1 \beta$ both in RAW264.7 cells and in plaque lesion areas, which suggests that MED can suppress inflammatory responses in atherosclerosis.

$\mathrm{NF}-\mathrm{KB}$ is a transcription factor involved in several inflammatory diseases, including atherosclerosis. The activation of NF- $\mathrm{KB}$ has been observed at different stages of atherosclerosis [13]. The binding of ox-LDL to LOX-1 can activate NF- $\mathrm{KB}$ signaling, thus leading to enhanced macrophage foam cell formation and proinflammatory cytokine production. Our data show that MED could significantly inhibit ox-LDL/LOX-1-induced activation of NF- $\mathrm{KB}$ signaling, which suggests that MED inhibits macrophage foam cell formation and activation at least in part by blocking NF- $\mathrm{kB}$ signaling.

The most significant finding of this current study is that MED could dramatically suppress atherosclerosis in $A p o E^{-/-}$mice fed a high fat diet. In addition to inhibiting inflammation and foam cell formation, we found that MED could significantly reduce the levels of blood fats, such as total triglyceride, total cholesterol, high-density lipoprotein, and low-density lipoprotein in mice (Additional file 3: Figure S3). These features might all contribute to the anti-atherogenic activity of MED. Therefore, MED exhibits the anti-atherogenic activity both in vitro and in vivo, which suggests that MED might represent a novel drug candidate for the effective treatment of atherosclerosis.

Collectively, our results demonstrate that MED, a novel marine microbial compound, can inhibit macrophage foam cell formation and activation in vitro and suppress atherosclerosis in $A p o E^{-/-}$mice, at least in part by inhibiting NF-kB activation. Our findings suggest that MED represents is a potential lead compound for the development of novel anti-atherosclerotic drugs.

\section{Materials and methods Materials}

MED was isolated from the fermentation broth of D. sp. HLY-1, as previously described [19]. The identity of MED was confirmed by HRMS and ${ }^{1} \mathrm{H}$ and ${ }^{13} \mathrm{C}$ NMR analysis, and the purity of MED exceeded $95.7 \%$ according to HPLC analysis. MED was dissolved in dimethylsulfoxide (DMSO) and stored at $-20{ }^{\circ} \mathrm{C}$. DMSO, MTT, oil red O, and anti- $\beta$-actin antibody were obtained from SigmaAldrich (Sigma, St. Louis, MO, USA); IL-1 $\beta$ ELISA kit, IL6 ELISA kit, and TNF- $\alpha$ ELISA kit were obtained from eBioscience (eBioscience, SanDiego, CA, USA); DMEM was purchased from Gibco (Gibco, Grand Island,NY, USA); fetal bovine serum (FBS) was obtained from Hyclone (Thermo Scientific, IL, USA); Ox-LDL was purchased from Unionbiol (Beijing, China); anti-IкB- $\alpha$ antibody was obtained from Santa Cruz Biotechnology (Santa Cruz, CA, USA); antibodies against p65 and PARP were purchased from Cell Signaling Technology (Danvers, MA, USA); antibody against LOX-1 was obtained from R\&D systems (Minneapolis, MN, USA); high-fat diet was produced by Vital River Laboratories (Beijing, China) according to the formula from Harlan (TD.88137).

\section{Methods}

\section{Cell culture}

Murine macrophage cell RAW 264.7 cells were purchased from the American Type Cell Culture Collection. Cells were cultured in DMEM supplemented with $10 \%$ fetal bovine serum (FBS).

\section{Cytotoxicity assay}

The cytotoxicity of MED was analyzed using a MTT assay. A total of $7 \times 10^{3}$ cells/well were seeded into a 96-well plate. After incubation with MED for $24 \mathrm{~h}, 10 \mu \mathrm{l}$ MTT ( $5 \mathrm{mg} / \mathrm{ml}$, Sigma) was added to each well. Plates were incubated for $4 \mathrm{~h}$ before adding of $100 \mu \mathrm{l}$ lysis buffer $(10 \%$ SDS in $0.01 \mathrm{M} \mathrm{HCl}$ ). Absorbance was measured at $560 \mathrm{~nm}$ using a microplate reader.

\section{Western blot analysis}

Lysates for western blot analysis were prepared from cells and aortic tissues. A total of $30 \mu \mathrm{g}$ protein lysates of each sample were subjected to SDS-PAGE and transferred onto nitrocellulose membranes. Blots were incubated with appropriate specific primary antibodies overnight at $4{ }^{\circ} \mathrm{C}$. After washing three times for $15 \mathrm{~min}$ each with TBST (TBS $+0.1 \%$ Tween20), blots were incubated with horseradish-peroxidase-conjugated secondary antibody (Pierce, Rockford, IL, USA) and visualized by chemiluminescence. Band densities were quantified by densitometry using the Scion Image software and were normalized to the $\beta$-actin and PARP levels.

\section{Quantitative real-time PCR}

Total RNA was isolated using Trizol reagent (Invitrogen) according to the manufacturer's instructions. The cDNA was synthesized from $2 \mu \mathrm{g}$ total RNA using MMLV transcriptase (ToYoBo, Shanghai, China) with random primers, real-time PCR was performed using SYBR Premix ExTaq (TaKaRa, Dalian, China). Quantification was normalized to the amount of endogenous GAPDH.

\section{Cytokine assays}

Cells were seeded in 96-well plates $24 \mathrm{~h}$ prior to ox-LDL and MED treatment, and the concentrations of TNF- $\alpha$, IL-6, and IL-1 $\beta$ were determined using ELISA kits (eBioscience, San Diego, CA) according to the manufacturer's instructions. 
High-density lipoprotein (HDL), low-density lipoprotein (LDL), triglyceride (TG), and total cholesterol (TC)

Mice were euthanized and blood was collected. HDL, LDL, TG, and TC were measured using ELISA kits according to the manufacturer's instructions.

\section{Nuclear protein extraction}

After ox-LDL and MED treatments, cells were collected and then Buffer A (10 mM HEPES (pH 7.9), $10 \mathrm{mM} \mathrm{KCl}$, $0.1 \mathrm{mM}$ EDTA, $1 \mathrm{mM}$ DTT, and $0.5 \mathrm{mM}$ PMSF) was added. After incubation on ice for $20 \mathrm{~min}$, cells were suspended in Buffer A with $2.5 \% \mathrm{NP}$ - 40, vortexed for $10 \mathrm{~s}$ and then centrifuged at $12,000 \times g$ for $5 \mathrm{~min}$ at $4{ }^{\circ} \mathrm{C}$. Supernatants were collected to detect cytoplasmic proteins. Buffer B (20 mM HEPES (pH 7.9), 0.4 M NaCl, $1 \mathrm{mM}$ EDTA, $1 \mathrm{mM}$ DTT, and $1 \mathrm{mM}$ PMSF) was used to resuspend the precipitates, and the suspension was vortexed for $25 \mathrm{~min}$ at $4{ }^{\circ} \mathrm{C}$ and then centrifuged at $12,000 \times g$ for 5 min at $4{ }^{\circ} \mathrm{C}$. Supernatants were collected as nuclear extracts, and the protein concentrations were measured using the Bradford protein assay (Bio-Rad, Hercules, CA).

\section{Electrophoretic mobility shift assay}

A total of $10 \mu \mathrm{g}$ nuclear extract was incubated with $20 \mathrm{nM}$ biotin-labeled double- stranded oligonucleotide probes for $20 \mathrm{~min}$ at room temperature, and then were separated on a non-denaturing $6 \%(\mathrm{w} / \mathrm{v})$ polyacrylamide gel. The biotin-labeled oligonucleotide probes (NF-kB: 5' -AGT TGA GGG GAC TTT CCC AGG C-3', 3' -TCA ACT CCC CTG AAA GGG TCC G-5') were transferred from the polyacrylamide gel onto a nylon membrane. Bands were detected with a LightShift chemiluminescent EMSA kit (Pierce, Rockford, IL) according to the manufacturer's instruction.

High-fat diet-induced atherosclerosis in $\mathrm{ApoE}^{-/-}$mice Eight-week-old $A p o E^{-/-}$mice were fed a high-fat diet for 12 weeks to induce atherosclerosis. All experiments were approved by the Animal Care and Use Committee of Xiamen University (Protocol Number: XMULAC 2012 0001). Every effort was made to reduce animal suffering.

\section{Atherosclerotic lesion analysis}

Mice were euthanized and their hearts and aortas were isolated. The degree of atherosclerosis was assessed by determining lesion sizes on both pinned open aortas and serial cross-sections through the aortic root as previously described but with some modification [38-40]. The aorta was opened longitudinally along the ventral midline from the iliac arteries to the aortic root. After the branching vessels were treated, the aorta was pinned out flat on a black wax surface. Lesions were treated with $70 \%$ ethanol and then stained with Sudan IV for 15 min, destained with $80 \%$ ethanol, and then washed with PBS. Aortic images were analyzed using the Adobe Photoshop software; data are reported as the percentage of the aortic surface covered by lesions.

\section{Statistical analysis}

Data were collected from several independent experiments, with three replicates per experiment. All data were analyzed by one-way Anova with post-Tukey's post-test with the SPSS 16.0 software package: $p<0.05$ and $p<0.01$ were considered to indicate statistically significant differences. Bars in the graph represent standard deviation (S.D.).

\section{Additional files}

Additional file 1: Figure S1. There is no significant difference in body weight change between PBS control group and MED group during 8 weeks of HFD feeding.

Additional file 2: Figure S2. Inhibitory effects of MED on NF-KB activation in aortic arch tissue isolated from mice. Nuclear proteins were extracted from aortic arch tissue. Nuclear NF-kB p65 was detected by Western blot.

Representative images are shown from three independent experiments. (Control: normal chow-fed group, PBS: HFD-fed and PBS treated group, MED: HFD-fed and MED treated group).

Additional file 3: Figure S3. MED decreases the levels of blood fats in mice. Mice were euthanized and blood was collected. The levels of total triglyceride, total cholesterol, high density lipoprotein, and low density lipoprotein were measured using ELISA kits. (Control: normal chow-fed group, PBS: HFD-fed and PBS treated group, MED: HFD-fed and MED treated group). Values are shown as the mean \pm SD from three independent experiments. ${ }^{*} p<0.05 \mathrm{vs}$ PBS group.

\section{Competing interests}

The authors declare that they have no competing interests.

\section{Authors' contributions}

$X X, W L$ and $C Y$ designed the overall study; $X X, Y L, Q S, Z H$ and SY performed the experiments or data analysis; and $X X, W L$ and $C Y$ wrote the manuscript. All authors read and approved the final version of the manuscript.

\section{Acknowledgments}

This work was supported by grants from the Natural Science Foundation of China (81270277), and the Natural Science Foundation of Fujian Province of China (2010 J06014).

\section{Author details}

${ }^{1}$ The First Affiliated Hospital of Xiamen University, Xiamen, Fujian 361005, China. ${ }^{2}$ State Key Laboratory of Cellular Stress Biology, Innovation Center for Cell Signaling Network, School of Life Sciences, Xiamen University, Xiang-An South Road, Xiamen, Fujian 360112, China. ${ }^{3}$ Medical College, Xiamen University, Xiamen, China. ${ }^{4}$ School of Pharmaceutical Sciences, Shandong University, Jinan, Shandong 250012, China.

Received: 25 March 2015 Accepted: 20 May 2015

Published online: 26 May 2015

\section{References}

1. Libby P, Ridker PM, Maseri A. Inflammation and atherosclerosis. Circulation. 2002;105(9):1135-43.

2. Zhao Y, Liu Y, Zhang W, Xue J, Wu YZ, Xu W, et al. WIN55212-2 ameliorates atherosclerosis associated with suppression of pro-inflammatory responses in ApoE-knockout mice. Eur J Pharmacol. 2010;649(1-3):285-92. doi:10.1016/j.ejphar.2010.09.027.

3. Steinberg D. Low density lipoprotein oxidation and its pathobiological significance. J Biol Chem. 1997;272(34):20963-6. 
4. Robbesyn F, Salvayre R, Negre-Salvayre A. Dual role of oxidized LDL on the NF-kappaB signaling pathway. Free Radic Res. 2004;38(6):541-51.

5. Hansson GK. Inflammation, atherosclerosis, and coronary artery disease. N Engl J Med. 2005;352(16):1685-95. doi:10.1056/NEJMra043430.

6. Kirii H, Niwa T, Yamada Y, Wada H, Saito K, Iwakura Y, et al. Lack of interleukin-1beta decreases the severity of atherosclerosis in ApoE-deficient mice. Arterioscler Thromb Vasc Biol. 2003;23(4):656-60. doi:10.1161/ 01.ATV.0000064374.15232.C3.

7. Sawamura T, Kume N, Aoyama T, Moriwaki H, Hoshikawa H, Aiba Y, et al. An endothelial receptor for oxidized low-density lipoprotein. Nature. 1997;386(6620):73-7. doi:10.1038/386073a0.

8. Aoyama T, Chen M, Fujiwara H, Masaki T, Sawamura T. LOX-1 mediates lysophosphatidylcholine-induced oxidized LDL uptake in smooth muscle cells. FEBS Lett. 2000;467(2-3):217-20.

9. Li L, Sawamura T, Renier G. Glucose enhances human macrophage LOX-1 expression: role for LOX-1 in glucose-induced macrophage foam cell formation. Circ Res. 2004;94(7):892-901. doi:10.1161/01.RES.0000124920.09738.26.

10. Shi X, Niimi S, Ohtani T, Machida S. Characterization of residues and sequences of the carbohydrate recognition domain required for cell surface localization and ligand binding of human lectin-like oxidized LDL receptor. J Cell Sci. 2001;114(Pt 7):1273-82.

11. Kataoka H, Kume N, Miyamoto S, Minami M, Moriwaki H, Murase T, et al. Expression of lectinlike oxidized low-density lipoprotein receptor-1 in human atherosclerotic lesions. Circulation. 1999;99(24):3110-7.

12. Liu H, Jiang $D$, Zhang $S$, Ou B. Aspirin inhibits fractalkine expression in atherosclerotic plaques and reduces atherosclerosis in ApoE gene knockout mice. Cardiovasc Drugs Ther. 2010;24(1):17-24. doi:10.1007/s10557-009-6210-7.

13. Pamukcu B, Lip GY, Shantsila E. The nuclear factor-kappa B pathway in atherosclerosis: a potential therapeutic target for atherothrombotic vascular disease. Thromb Res. 2011;128(2):117-23. doi:10.1016/j.thromres.2011.03.025.

14. Li D, Mehta JL. Intracellular signaling of LOX-1 in endothelial cell apoptosis. Circ Res. 2009;104(5):566-8. doi:10.1161/CIRCRESAHA.109.194209.

15. Chen M, Masaki T, Sawamura T. LOX-1, the receptor for oxidized low-density lipoprotein identified from endothelial cells: implications in endothelial dysfunction and atherosclerosis. Pharmacol Ther. 2002;95(1):89-100.

16. Ogura S, Kakino A, Sato Y, Fujita Y, Iwamoto S, Otsui K, et al. Lox-1: the multifunctional receptor underlying cardiovascular dysfunction. Circ J. 2009;73(11):1993-9.

17. Li DY, Chen HJ, Mehta JL. Statins inhibit oxidized-LDL-mediated LOX-1 expression, uptake of oxidized-LDL and reduction in PKB phosphorylation. Cardiovasc Res. 2001;52(1):130-5.

18. Hofnagel O, Luechtenborg B, Eschert H, Weissen-Plenz G, Severs NJ, Robenek H. Pravastatin inhibits expression of lectin-like oxidized low-density lipoprotein receptor-1 (LOX-1) in Watanabe heritable hyperlipidemic rabbits: a new pleiotropic effect of statins. Arterioscler Thromb Vasc Biol. 2006;26(3):604-10. doi:10.1161/01.ATV.0000201073.45862.8b.

19. Lin X, Huang Y, Fang M, Wang J, Zheng Z, Su W. Cytotoxic and antimicrobial metabolites from marine lignicolous fungi, Diaporthe sp. FEMS Microbiol Lett. 2005;251(1):53-8. doi:10.1016/j.femsle.2005.07.025.

20. Takao K, Watanabe G, Yasui H, Tadano K. Total synthesis of (+/-)-mycoepoxydiene, a novel fungal metabolite having an oxygenbridged cyclooctadiene skeleton. Org Lett. 2002;4(17):2941-3.

21. Wang J, Zhao B, Zhang W, Wu X, Wang R, Huang Y, et al. Mycoepoxydiene, a fungal polyketide, induces cell cycle arrest at the G2/M phase and apoptosis in HeLa cells. Bioorg Med Chem Lett. 2010;20(23):7054-8. doi:10.1016/j.bmcl.2010.09.105.

22. Chen Q, Chen T, Li W, Zhang W, Zhu J, Li Y, et al. Mycoepoxydiene inhibits lipopolysaccharide-induced inflammatory responses through the suppression of TRAF6 polyubiquitination [corrected]. PLOS One. 2012;7(9):e44890. doi:10.1371/journal.pone.0044890.

23. Zhu J, Chen Q, Xia X, Mo P, Shen Y, Yu C. Mycoepoxydiene suppresses RANKL-induced osteoclast differentiation and reduces ovariectomy-induced bone loss in mice. Appl Microbiol Biotechnol. 2013;97(2):767-74. doi:10.1007/s00253-012-4146-5.

24. Xia XC, Chen Q, Liu K, Mo PL, Zhu JW, Zhuang MQ, et al. Mycoepoxydiene inhibits antigen-stimulated activation of mast cells and suppresses IgE-mediated anaphylaxis in mice. Int Immunopharmacol. 2013;17(2):336-41. doi:10.1016/j.intimp.2013.06.029.

25. de Vries-van der Weij J, Toet K, Zadelaar S, Wielinga PY, Kleemann R, Rensen $P C$, et al. Anti-inflammatory salicylate beneficially modulates pre-existing atherosclerosis through quenching of NF-kappaB activity and lowering of cholesterol. Atherosclerosis. 2010;213(1):241-6. doi:10.1016/j.atherosclerosis. 2010.09.006.

26. van Diepen JA, Berbee JF, Havekes LM, Rensen PC. Interactions between inflammation and lipid metabolism: relevance for efficacy of antiinflammatory drugs in the treatment of atherosclerosis. Atherosclerosis. 2013;228(2):306-15. doi:10.1016/j.atherosclerosis.2013.02.028.

27. Mendez-Fernandez YV, Stevenson BG, Diehl CJ, Braun NA, Wade NS, Covarrubias R, et al. The inhibitory FcgammaRllb modulates the inflammatory response and influences atherosclerosis in male apoE(-/-) mice. Atherosclerosis. 2011;214(1):73-80. doi:10.1016/j.atherosclerosis. 2010.10.018.

28. Boyle JJ. Macrophage activation in atherosclerosis: pathogenesis and pharmacology of plaque rupture. Curr Vasc Pharmacol. 2005;3(1):63-8.

29. Xu S, Liu Z, Huang Y, Le K, Tang F, Huang H, et al. Tanshinone II-A inhibits oxidized LDL-induced LOX-1 expression in macrophages by reducing intracellular superoxide radical generation and NF-kappaB activation. Transl Res. 2012;160(2):114-24. doi:10.1016/j.trsl.2012.01.008.

30. Zhou J, Moller J, Ritskes-Hoitinga M, Larsen ML, Austin RC, Falk E. Effects of vitamin supplementation and hyperhomocysteinemia on atherosclerosis in apoE-deficient mice. Atherosclerosis. 2003;168(2):255-62.

31. Lusis AJ. Atherosclerosis. Nature. 2000;407(6801):233-41. doi:10.1038/35025203.

32. Berliner JA, Navab M, Fogelman AM, Frank JS, Demer LL, Edwards PA, et al. Atherosclerosis: basic mechanisms. Oxidation, inflammation, and genetics. Circulation. 1995;91(9):2488-96.

33. Ross R. The pathogenesis of atherosclerosis: a perspective for the 1990s. Nature. 1993;362(6423):801-9. doi:10.1038/362801a0.

34. Chen H, Li D, Sawamura T, Inoue K, Mehta JL. Upregulation of LOX-1 expression in aorta of hypercholesterolemic rabbits: modulation by losartan. Biochem Biophys Res Commun. 2000;276(3):1100-4. doi:10.1006/bbrc.2000.3532.

35. Honjo M, Nakamura K, Yamashiro K, Kiryu J, Tanihara H, McEvoy LM, et al. Lectin-like oxidized LDL receptor-1 is a cell-adhesion molecule involved in endotoxin-induced inflammation. Proc Natl Acad Sci U S A. 2003;100(3):1274-9. doi:10.1073/pnas.0337528100.

36. Mehta JL, Sanada N, Hu CP, Chen J, Dandapat A, Sugawara F, et al. Deletion of LOX-1 reduces atherogenesis in LDLR knockout mice fed high cholesterol diet. Circ Res. 2007;100(11):1634-42. doi:10.1161/CIRCRESAHA.107.149724.

37. Wu Z, Sawamura T, Kurdowska AK, Ji HL, Idell S, Fu J. LOX-1 deletion improves neutrophil responses, enhances bacterial clearance, and reduces lung injury in a murine polymicrobial sepsis model. Infect Immun. 2011;79(7):2865-70. doi:10.1128/IAl.01317-10

38. Seimon TA, Wang Y, Han S, Senokuchi T, Schrijvers DM, Kuriakose G, et al. Macrophage deficiency of p38alpha MAPK promotes apoptosis and plaque necrosis in advanced atherosclerotic lesions in mice. J Clin Invest. 2009;119(4):886-98. doi:10.1172/JCl37262.

39. Sekiya M, Osuga J, Nagashima S, Ohshiro T, Igarashi M, Okazaki H, et al. Ablation of neutral cholesterol ester hydrolase 1 accelerates atherosclerosis. Cell Metab. 2009;10(3):219-28. doi:10.1016/j.cmet.2009.08.004.

40. Thorp E, Li G, Seimon TA, Kuriakose G, Ron D, Tabas I. Reduced apoptosis and plaque necrosis in advanced atherosclerotic lesions of Apoe-/- and Ldlr-/- mice lacking CHOP. Cell Metab. 2009;9(5):474-81. doi:10.1016/ j.cmet.2009.03.003.

\section{Submit your next manuscript to BioMed Central and take full advantage of:}

- Convenient online submission

- Thorough peer review

- No space constraints or color figure charges

- Immediate publication on acceptance

- Inclusion in PubMed, CAS, Scopus and Google Scholar

- Research which is freely available for redistribution 